\title{
ESPAÇOS LIVRES, ÁREAS VERDES E COBERTURA VEGETAL NO BAIRRO ALTO DA XV, CURITIBA/PR
}

\author{
Alexandre Theobaldo Buccheri Filho ${ }^{1}$ \\ João Carlos Nucci2
}

\begin{abstract}
Resumo: Entre os órgãos de pesquisa, ensino, planejamento e sociedades científicas são encontrados diferentes interpretações para os termos área verde, espaço livre, cobertura vegetal, áreas destinadas à conservação da natureza, florestas urbanas, entre outros. Este artigo apresenta e aplica, em um bairro do município de Curitiba (PR), uma proposta de classificação para os espaços livres e para o verde urbano, como sugestão de conceitos, métodos e técnicas aplicados ao planejamento da paisagem urbana.
\end{abstract}

Palavras-chave: Espaço livre; Área verde; Cobertura vegetal; Curitiba.

\section{Introdução}

O crescimento contínuo das áreas urbanizadas vem provocando modificações na paisagem com o conseqüente comprometimento da qualidade do meio físico. Tanto o crescimento horizontal quanto o vertical das cidades ocorrem em detrimento da qualidade dos recursos naturais (solo, água, ar e organismos) e dos espaços livres.

Ar fresco, água potável, certa quantidade de alimento por dia, espaço para dormir e estar, pessoas para interagir, etc. são necessidades humanas que não mudam ao longo da vida (ANDREWS, 1976); porém, cada vez mais, estas necessidades são consideradas como "as novas raridades e em torno das quais se desenvolve uma intensa luta" (LEFEBVRE, 1969).

Todas as necessidades humanas deveriam ser consideradas no planejamento urbano mas "na sociedade burguesa, preocupações econômicas constituem o tema principal da investigação social; todas as outras considerações humanas são secundárias" (LEFEBVRE, 1969). MARCUS e DETWYLER (1972) afirmam que, "(...) tradicionalmente, os fatores econômicos têm decidido o uso da terra sem levar em consideração os fatores ecológicos". Para ROCHA (1991) "Na realidade, o comportamento humano é regido não só por parâmetros éticos e sociais, mas também por fatores ambientais. Ora, em um ambiente urbano que constitui o verdadeiro habitat e 'nicho' do ser humano, obviamente, ele deve ser (ou deveria ser) o ponto central de referência quando da tomada de qualquer decisão pela autoridade constituída, ou no nível da própria cidadania".

A Lei Federal $n^{0} 10.257$, de 10 de julho de 2001, também conhecida por Estatuto da Cidade, e talvez a mais importante na atualidade em se tratando do planejamento urbano, estabelece diretrizes para 0 uso da propriedade urbana em prol do bem coletivo, da segurança e do bem-estar dos cidadãos, bem como do equilíbrio ambiental (Art. 10 ${ }^{\circ}$, Parágrafo único).

Segundo essa Lei, a política urbana deve ter por objetivo ordenar o pleno desenvolvimento das funções sociais da cidade e da propriedade urbana, mediante certas diretrizes gerais, entre elas, a de se garantir o direito às cidades sustentáveis (Art. $2^{\circ}$, inc. I), ao planejamento do desenvolvimento das cidades, de modo a evitar e corrigir as distorções do crescimento urbano e seus efeitos negativos sobre o meio ambiente (Art. $2^{\circ}$, inc. IV).

A política urbana ainda deve garantir 0 direito ao ordenamento e controle do uso do solo, de forma a evitar a poluição e a degradação ambiental (Art $2^{\circ}$, inc. VI), adoção de padrões de produção e consumo e de expansão urbana, compatíveis com os limites da sustentabilidade ambiental (Art $2^{\circ}$, inc. VIII) e a proteção, preservação e recuperação do meio ambiente natural e construído (Art $2^{\circ}$, inc. XII).

Além da clara preocupação com a qualidade ambiental das cidades, o Estatuto (BRASIL, 2001) aponta como diretrizes da política urbana a garantia da oferta de equipamentos urbanos

${ }_{1}^{1}$ Geógrafo e Mestrando (DGeog - UFPR) - Rua Raphael Papa, 413 cs. 1 - cep. 82530-190, Jardim Social - Curitiba/Pr - (abuccheri@terra.com.br) Bolsista da CAPES.

${ }^{2}$ Biólogo (IB-USP), doutor em Geografia Física (DG-FFLCH-USP), professor do DGeog.- UFPR - (nucci@ufpr.br) 
e comunitários adequados aos interesses e necessidades da população (Art. $2^{\circ}$, inc. V) e a ordenação e controle do uso do solo, de forma a evitar o parcelamento do solo, a edificação ou 0 uso excessivo ou inadequado em relação à infra-estrutura urbana (Art. $2^{\circ}$, inc. VI).

"Equilíbrio ambiental", "cidades sustentáveis", "efeitos negativos sobre o meio ambiente", "poluição e degradação ambiental", "limites da sustentabilidade ambiental" e "proteção, preservação e recuperação do meio ambiente natural", entre outros encontrados no Estatuto da Cidade, são temas que dizem respeito, necessariamente, ao "verde urbano" que, apesar de sua importância, não se apresenta como uma necessidade óbvia na cena urbana, sendo negligenciado no planejamento do desenvolvimento das cidades. Todavia, a necessidade que 0 homem tem de vegetação extrapola um valor meramente sentimental ou estético (MONTEIRO, 1976), desempenhando um importante papel nas áreas urbanizadas no que se refere à qualidade ambiental (LOMBARDO, 1990).

As questões relativas ao equilibrio ambiental e a sustentabilidade, bem como aquelas sobre a oferta de equipamentos urbanos e comunitários, levantadas pelo Estatuto da Cidade (BRASIL, 2001), poderiam ser discutidas no âmbito da Ecologia da Paisagem, área que se preocupa com o ordenamento da paisagem com ênfase nos aspectos ecológicos e, mais especificamente, em se tratando da paisagem urbanizada, com a conservação da natureza e com o ordenamento do verde urbano procurando um ambiente saudável e viável em longo prazo para o uso humano. Procura-se, portanto, uma regulamentação dos usos do solo e dos recursos ambientais, salvaguardando a capacidade dos ecossistemas e o potencial recreativo da paisagem, retirandose o máximo proveito do que a vegetação pode fornecer para a melhoria da qualidade ambiental.

Além disso, essas questões, também apontam para um aumento da produtividade biológica dentro das cidades, ou seja, para um aumento de todas as formas possíveis de vegetação em áreas urbanas.

A quantificação e a configuração espacial do "verde urbano" podem ser utilizadas como instrumentos e parâmetros de avaliação da qualidade ambiental em áreas urbanas $(\mathrm{NUCCl} e$ CAVALHEIRO, 1999; NUCCI, 2001). DIAS (2002) aponta para a importância de indicadores que ajudem a evidenciar aos habitantes 0 grau de saúde de sua sociedade e os êxitos ou fracassos das políticas governamentais adotadas. Coloca a importância do levantamento regular dos indicadores, como modelos que simplificam um tema complexo a uns tantos números (índices), que possam ser facilmente tomados e entendidos por quem elabora políticas e pelo público em geral. Isso permitiria, por exemplo, estabelecer comparações entre cidades e entre bairros do próprio município.

A cobertura vegetal como indicador já é considerada pelo Programa de Indicadores Ambientais para Blumenau, desenvolvido pela Fundação Municipal do Meio Ambiente (Faema), lançado em 1997. Ela faz parte da composição de Índices de Sustentabilidade de Blumenau (SC), configurados em um "Sustentômetro" que é uma expressão gráfica que permite visualizar facilmente a condição ambiental local (DIAS, 2002).

Todavia, uma das dificuldades de se considerar o "verde urbano" no planejamento é a existência de uma enorme confusão na conceituação de termos utilizados por várias prefeituras do país que consideram, por exemplo, como áreas verdes, locais onde não existe sequer uma única árvore (LIMA et. al, 1994), fazendo com que a comparação de índices entre cidades seja um equívoco, pois o índice desacompanhado da definição dos termos, da escala espacial e do método de coleta dos dados, não estabelece parâmetros de comparação (NUCCl, 2001).

Com o objetivo de colaborar com os estudos para a padronização de conceitos, CAVALHEIRO et al. (1999) forneceram algumas sugestões que poderiam ser consideradas como uma possível resposta para o problema levantado.

Neste trabalho, portanto, realizou-se uma aplicação dos conceitos, métodos e técnicas para se identificar, classificar, quantificar e mapear os espaços livres, as áreas verdes e a cobertura vegetal em áreas urbanas, como sugerido por CAVALHEIRO et al. (1999).

0 teste dessa metodologia foi realizado no bairro Alto da XV no município de Curitiba, Estado do Paraná, e os resultados foram comparados com outros levantamentos conforme os trabalhos citados na Tabela 1, os estudos de NUCCI (2001) no Distrito de Santa Cecília, no Município de São Paulo e NUCCl et al. (2000) em bairros do Município de Guarulhos/SP, já executados segundo a mesma metodologia.

\section{Revisão Bibliográfica}

CAVALHEIRO et al. (1999) sugeriram os seguintes tópicos para uma tentativa de padronização de conceitos:

Primeiramente deve-se entender que a legislação brasileira estabelece que o município está dividido em zona urbana, de expansão urbana e zona rural. A zona urbana, cujo perímetro é declarado por lei municipal, embora não explicitamen-te colocada na legislação, estaria constituída por três sistemas: 
- Sistema de espaços com construções (habitação, indústria, comércio, hospitais, escolas, etc);

- Sistema de espaços livres de construção (praças, parques, águas superficiais, etc.) e,

- Sistema de espaços de integração urbana (rede rodoferroviária).

O espaço livre de construção é definido como espaço urbano ao ar livre, destinado a todo tipo de utilização que se relacione com caminhadas, descanso, passeios, práticas de esportes e, em geral, a recreação e entretenimento em horas de ócio; os locais de passeios a pé devem oferecer segurança e comodidade com separação total da calçada em relação aos veículos; os caminhos devem ser agradáveis, variados e pitorescos; os locais onde as pessoas se locomovem por meios motorizados não devem ser considerados como espaços livres. Os espaços livres podem ser privados, potencialmente coletivos ou públicos e podem desempenhar, principalmente, funções estética, de lazer e ecológico-ambiental, entre outras.

As áreas verdes são um tipo especial de espaços livres onde 0 elemento fundamental de composição é a vegetação. Elas devem satisfazer três objetivos principais: ecológico-ambiental, estético e de lazer. Vegetação e solo permeável (sem laje) devem ocupar, pelo menos, $70 \%$ da área; devem servir à população, propiciando um uso e condições para recreação. Canteiros, pequenos jardins de ornamentação, rotatórias e arborização não podem ser considerados áreas verdes, mas sim "verde de acompanhamento viário", que com as calçadas (sem separação total em relação aos veículos) pertencem à categoria de espaços construídos ou espaços de integração urbana.

Cobertura vegetal é a projeção do verde em cartas planimétricas e pode ser identificada por meio de fotografias aéreas, sem auxilio de esteroscopia. A escala da fotografia deve acompanhar os índices de cobertura vegetal; deve ser considerada a localização e a configuração das manchas em mapas. Considera-se toda a cobertura vegetal existente nos três sistemas (espaços construídos, espaços livres e espaços de integração) e as encontradas nas Unidades de Conservação, que na sua maioria restringem 0 acesso ao público, inclusive na zona rural.

A Fig. 1 apresenta um fluxograma com base na proposta de CAVALHEIRO et al. (1999).
Essa conceituação de termos para o "verde urbano", sugerida por CAVALHEIRO et al. (1999), já foi aplicada em algumas áreas do município de Guarulhos/SP (NUCCl et al., 2000; NUCCI e ITO, 2002), do município de São Paulo (NUCCl, 2001) e do município de Curitiba (NUCCl et al., 2003), mostrando-se de fácil entendimento e de grande utilidade para o planejamento e avaliação da qualidade dos espaços urbanos.

Portanto, antes de se pensar em quantificar o "verde urbano" na busca de índices, deve-se refletir sobre o conceito daquilo que se está quantificando, e como está sendo feita esta quantificação, ou seja, os métodos e as técnicas.

A grande confusão na conceituação de termos não impede, porém, a procura de possiviveis índices para as diferentes formas do "verde urbano".

Sobre a quantificação, OKE (1973 apud LOMBARDO, 1985) estima que um índice de cobertura vegetal na faixa de $30 \%$ seja o recomendável para proporcionar um adequado balanço térmico em áreas urbanas, sendo que áreas com índice de arborização inferior a $5 \%$ determinam características semelhantes às de um deserto.

Para SUKOPP et al. (1979) as áreas centrais das cidades podem ser consideradas como um "deserto de epífitas", batizado por DOUGLAS (1983) como "deserto florístico".

A cidade ideal, segundo SUKOPP e WERNER (1991), que apresentaria as condições ideais para a conservação da natureza e da paisagem, poderia edificar ou pavimentar, aproximadamente, somente dois terços da superfície do centro, ou seja, $33 \%$ da área central da cidade deveriam ser permeáveis e não edificados ${ }^{1} \mathrm{e}$ deveriam apresentar ampla conexão entre a vegetação da zona rural e a das zonas centrais, com uma redução dos gradientes entre esses dois tipos de uso.

Outros índices de Espaços Livres, Áreas Verdes e Cobertura Vegetal, sugeridos por diversos países, podem ser consultados em NUCCI (2001).

A aplicação indiscriminada de índices, oriundos de realidades diferentes sejam elas físicas, sociais, econômicas ou culturais, certamente não surtirá 0 efeito desejado. Portanto, colecionar índices é mais um exercício de reflexão, um ponto de partida para se pensar as condições do "verde urbano" de cada cidade em particular.

${ }_{1}$ Sobre os usos dos termos "construção" e "edificação" em se tratando de Espaços Livres, indica-se o trabalho de CAVALHEIRO, PRESOTTO e ROCHA (2003). 


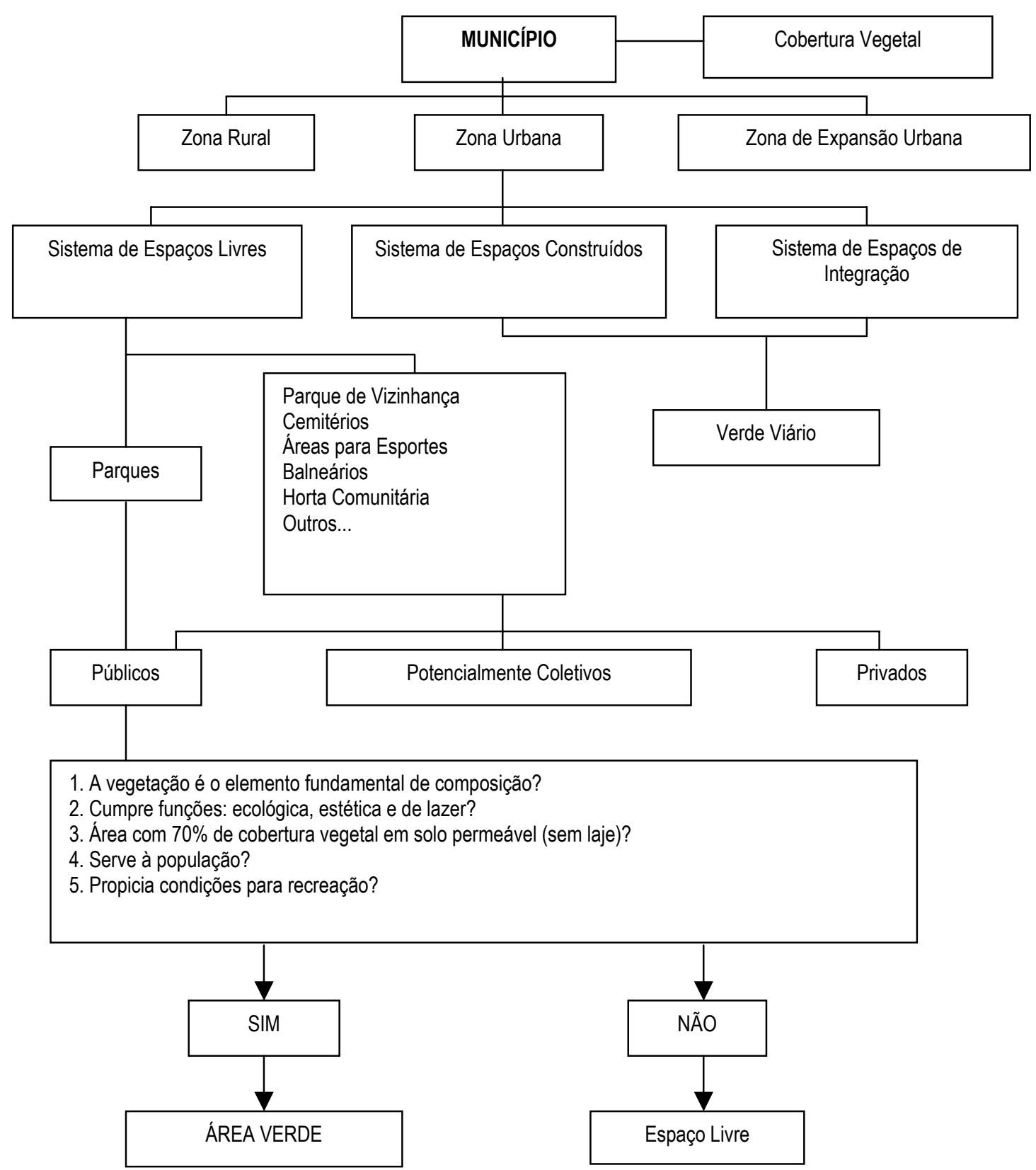

Figura 1 Organograma de Classificação do Verde Urbano com base em CAVALHEIRO et al. 1999 (Organização: João Carlos Nucci, 2004).

Por exemplo, o índice de cobertura vegetal recomendável para proporcionar um adequado balanço térmico para a cidade de Belém (PA), certamente, será diferente do índice recomendável para Curitiba (PR).

Porém, se para OKE (1973 apud LOMBARDO, 1985), que levou em consideração características de cidades canadenses, esse índice deve estar na faixa de $30 \%$ e que as áreas com índice de arborização inferior a $5 \%$ determinariam características semelhantes às de um deserto, possivelmente, nas regiões tropicais esse índice deveria ser maior. Na verdade, faltam estudos suficientes para se designar os índices "ideais" para as cidades brasileiras.

Isso não quer dizer que a quantificação deva ser desprezada já que a comparação entre índices de diferentes 
bairros da mesma cidade, ou entre bairros de cidades diferentes, mas com as mesmas características, é perfeitamente possível, desde que se utilizem métodos e técnicas semelhantes.

Além da quantificação, um estudo da distribuição espacial do "verde urbano" é, também, de fundamental importância como parâmetro de avaliação das condições ambientais e de disponibilidade de uso pela população.

DOUGLAS (1983) coloca que em áreas urbanas, a contínua fragmentação dos hábitats naturais, os distúrbios e aumento do isolamento dos indivíduos em "hábitats de ilhas", têm causado uma geral redução na riqueza de espécies: espécies mais sensiveis são expulsas pelas agressivas que conseguem sobreviver em condições mais perturbadas.

Por esse motivo, entre outros, a quantificação deveria vir acompanhada da configuração espacial, o que permitiria, inclusive, avaliar as formas e o grau de conectividade das manchas de vegetação.

Uma proposta de classificação das diferentes formas geométricas da cobertura vegetal é encontrada em JIM (1989). Um estudo realizado em Hong Kong, faz uma classificação dos tipos de configurações das manchas de cobertura vegetal, Treecanopy cover (Figura 2), estudadas por meio de fotografias aéreas na escala de 1:8.000 (1986) e verificação de campo com cartas nas escalas 1:2.500 e 1:5.000, reduzindo, posteriormente, os resultados para a escala 1:20.000.

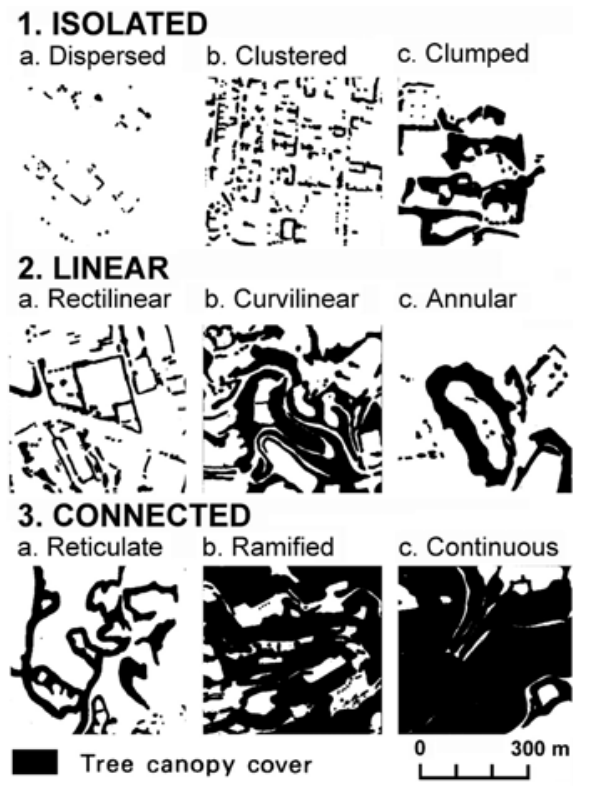

Figura 2 Esquema de classificação da distribuição espacial da cobertura vegetal (Jim, 1989).
Resultados de levantamentos, levando-se em consideração a terminologia para o verde urbano proposta por CAVALHEIRO et al. (1999), realizados por NUCCI (2001) no bairro de Santa Cecília no município de São Paulo, com base em fotografias aéreas na escalas 1:10.000 e por NUCCl e ITO (2002) no Jardim Tranqüilidade no Município de Guarulhos, na escala 1:6.000, apontam para áreas com alto grau de urbanização e uma quantidade insuficiente de cobertura vegetal (de 4 a $7 \%$ ) mal distribuída e desconexa.

Utilizando o mesmo procedimento, NUCCl et al. (2003) encontraram para o bairro Centro de Curitiba (PR), com base em interpretação de fotografias aéreas, coloridas, na escala 1:8.000, o valor de $12,56 \%$ para a cobertura vegetal, classificada com base nas categorias sugeridas por JIM (1989). As partes nordeste e leste do bairro apresentam uma maior quantidade e conectividade na cobertura vegetal, enquanto a parte mais central pode ser considerada um deserto florístico, sustentando cobertura vegetal apenas em algumas praças isoladas.

A Tab. 1 resume os resultados dos trabalhos desenvolvidos, segundo métodos semelhantes, e passíveis de comparação.

Tabela 1 Valores de cobertura vegetal para várias localidades.

\begin{tabular}{|c|c|c|c|c|}
\hline \multirow{2}{*}{ Localidade } & \multirow{2}{*}{$\begin{array}{l}\text { Escala da } \\
\text { foto aérea }\end{array}$} & \multirow{2}{*}{ Fonte } & \multicolumn{2}{|c|}{ Cobertura Vegetal } \\
\hline & & & $\%$ & $\mathrm{~m}^{2} /$ hab. \\
\hline $\begin{array}{l}\text { Distrito de } \\
\text { Santa } \\
\text { Cecilia (1) }\end{array}$ & $\begin{array}{c}1: 10.000 \\
\text { preto e branco / } \\
1989\end{array}$ & NUCCI (2001) & 7 & 2,96 \\
\hline $\begin{array}{l}\text { Jd. } \\
\text { Tranqüilidade } \\
\text { (2) }\end{array}$ & $\begin{array}{c}1: 6.000 \text { - colorida } \\
2000\end{array}$ & $\begin{array}{l}\text { NUCCl e ITO } \\
(2002)\end{array}$ & 4 & 2,52 \\
\hline $\begin{array}{l}\text { Centro de } \\
\text { Curitiba (3) }\end{array}$ & $\begin{array}{c}1: 8.000 \text { - colorida } \\
2000\end{array}$ & NUCCi et al (2003) & 12,56 & 12,70 \\
\hline $\begin{array}{l}\text { Município de } \\
\text { Curitiba }\end{array}$ & --- & HARDT (1994) & 60 & --- \\
\hline $\begin{array}{l}\text { Porto Alegre } \\
\text { (Área central) }\end{array}$ & $1: 8.000$ & $\begin{array}{c}\text { RUSZCZYK } \\
(1986)\end{array}$ & $\begin{array}{c}\text { de } 7 a \\
15\end{array}$ & --- \\
\hline $\begin{array}{l}\text { Cidade de } \\
\text { Maringá }\end{array}$ & -- & $\begin{array}{l}\text { HENKE-OLIVEIRA } \\
\text { et al. (1994) }\end{array}$ & -- & 20,6 \\
\hline
\end{tabular}

Observações:

(1) O Distrito de Santa Cecilia está localizado na área central do Município de São Paulo (SP).

(2) $0 \mathrm{~J}$. Tranqüilidade é um bairro próximo ao Centro do município de Guarulhos (SP)

(3) 0 Centro de Curitiba é um bairro da capital do Paraná.

Organização: NUCCl et al. (2003).

É importante observar que, segundo a terminologia proposta por CAVALHEIRO et al. (1999), o índice de cobertura 
vegetal não deve ser confundido com o índice de áreas verdes, já que no cálculo deste não devem ser consideradas as copas de árvores, canteiros, pequenos jardins de ornamentação e rotatórias, pois são áreas que não podem propiciar um uso e condições para recreação.

Além das questões mais relacionadas à qualidade ambiental, o Estatuto da Cidade (BRASIL, 2001), como já visto, também indica diretrizes para a Política Urbana que garantam a oferta de equipamentos urbanos e comunitários.

Entre os diversos equipamentos urbanos estão aqueles que devem propiciar ao cidadão oportunidades de utilização do tempo não obrigatório (lazer) com experiência de livre escolha (recreação). Nesse caso, o sistema de espaços livres tem uma grande parcela de responsabilidade em fornecer opções para que a população encontre possibilidades de escolha para a sua recreação, inclusive ao ar livre.

Os espaços livres poderiam ser classificados segundo suas tipologias (particulares, potencialmente coletivos e públicos), suas categorias (praças, parques, jardins, etc.) e disponibilidades (faixas etárias, $\mathrm{m}^{2} / \mathrm{hab}$., área mínima, distância da residência, etc.), de modo a assegurar a utilização de todos os cidadãos (GRÖNING, 1976; RICHTER, 1981 apud NUCCI, 2001). Uma sugestão de índices urbanísticos para o Sistema de Espaços Livres pode ser consultada na Tab. 2.

Tabela 2 Sugestão de índices urbanísticos para espaços livres (JANTZEN, 1973 apud CAVALHEIRO e DEL PICCHIA, 1992).

\begin{tabular}{|c|c|c|c|c|}
\hline Categorias & $\mathrm{m}^{2} / \mathrm{hab}$ & Área mínima & Distância da resid. & Propriedade \\
\hline $\begin{array}{c}\text { Vizinhança } \\
\text { até } 6 \text { anos } \\
6 \text { a } 10 \text { anos } \\
10 \text { a } 17 \text { anos }\end{array}$ & $\begin{array}{l}0,75 \\
0,75 \\
0,75\end{array}$ & $\begin{array}{c}150 \mathrm{~m}^{2} \\
450 \mathrm{~m}^{2} \\
5.000 \mathrm{~m}^{2}\end{array}$ & $\begin{array}{l}\text { até } 100 \mathrm{~m} \\
\text { até } 500 \mathrm{~m} \\
1000 \mathrm{~m}\end{array}$ & $\begin{array}{l}\text { públ. ou partic. } \\
\text { públ. ou partic. público }\end{array}$ \\
\hline parque de bairro & 6,0 & 10 ha & $1.000 \mathrm{~m}$ ou $10 \mathrm{~min}$. & público \\
\hline $\begin{array}{l}\text { parque distrital ou } \\
\text { setorial }\end{array}$ & $6,0-7,0$ & 100 ha & $1200 \mathrm{~m}$ ou $30 \mathrm{~min} . / \mathrm{veículo}$ & público \\
\hline parque regional & s/ref. & $\begin{array}{c}200 \text { ha } \\
\text { área com água }\end{array}$ & $\begin{array}{c}\text { qualquer parte } \\
\text { da cidade }\end{array}$ & público \\
\hline cemitério & 4,5 & s/ref. & s/ ref. & públ. ou partic. \\
\hline área para esporte & 5,5 & $\begin{array}{c}3-5 \text { ha } \\
1.500 \text { hab. }\end{array}$ & $\begin{array}{l}\text { perto das } \\
\text { escolas }\end{array}$ & públ. ou partic. \\
\hline balneário & $1,0-1 / 10$ & 2 ha $\quad 0,2$ ha & perto das escolas & públ. ou partic. \\
\hline horta comunitária & 12,0 & $300 \mathrm{~m}^{2}$ & $\mathrm{~s} /$ ref & públ. ou partic. \\
\hline verde viário & $\mathrm{s} /$ ref. & s/ ref. & junto ao sistema viário & público \\
\hline
\end{tabular}

Como não bastam espaços livres com centros esportivos onde a área construída e os equipamentos ocupem quase a totalidade do espaço, não restando quase nada que favoreça um contato maior do indivíduo com a natureza, principalmente com a vegetação, dentro das opções de recreação ao ar livre devem também ser alocados espaços livres especiais onde 0 elemento fundamental de composição é a vegetação; estes espaços devem cumprir três objetivos principais: ecológico-ambiental, estético e de lazer nos quais a vegetação e solo permeável (sem laje) devem ocupar, pelo menos, $70 \%$ da área; devem servir à população, propiciando um uso e condições para recreação, ou seja, as áreas verdes segundo CAVALHEIRO et al. (1999).

\section{Materiais e Métodos}

Partindo-se da afirmação de que o verde é uma necessi- dade dentro das cidades e de que este precisa estar ao alcance de todos os cidadãos, resolveu-se aplicar as sugestões de CAVALHEIRO et al. (1999) no bairro Alto da XV, em Curitiba (PR) (Fig. 3), identificando, classificando, mapeando e quantificando a cobertura vegetal, os espaços livres e as áreas verdes, com 0 propósito de aprimorar 0 método, fornecer mais índices para possiveis comparações, e diagnosticar a situação do "verde" no bairro em questão.

Os passos realizados para o estudo estão organizados nos seguintes tópicos:

1. Delimitação do bairro utilizando a carta Bairro Alto da XV (CURITIBA, 2003), na escala 1:10.000.

2. Cópias coloridas e reduzidas para a escala 1:10.000 das fotografias aéreas, coloridas, na escala 1:8.000, de dez/2000 (Fiducial Ltda, PMC/COHAB) e adquiridas junto ao Instituto de 


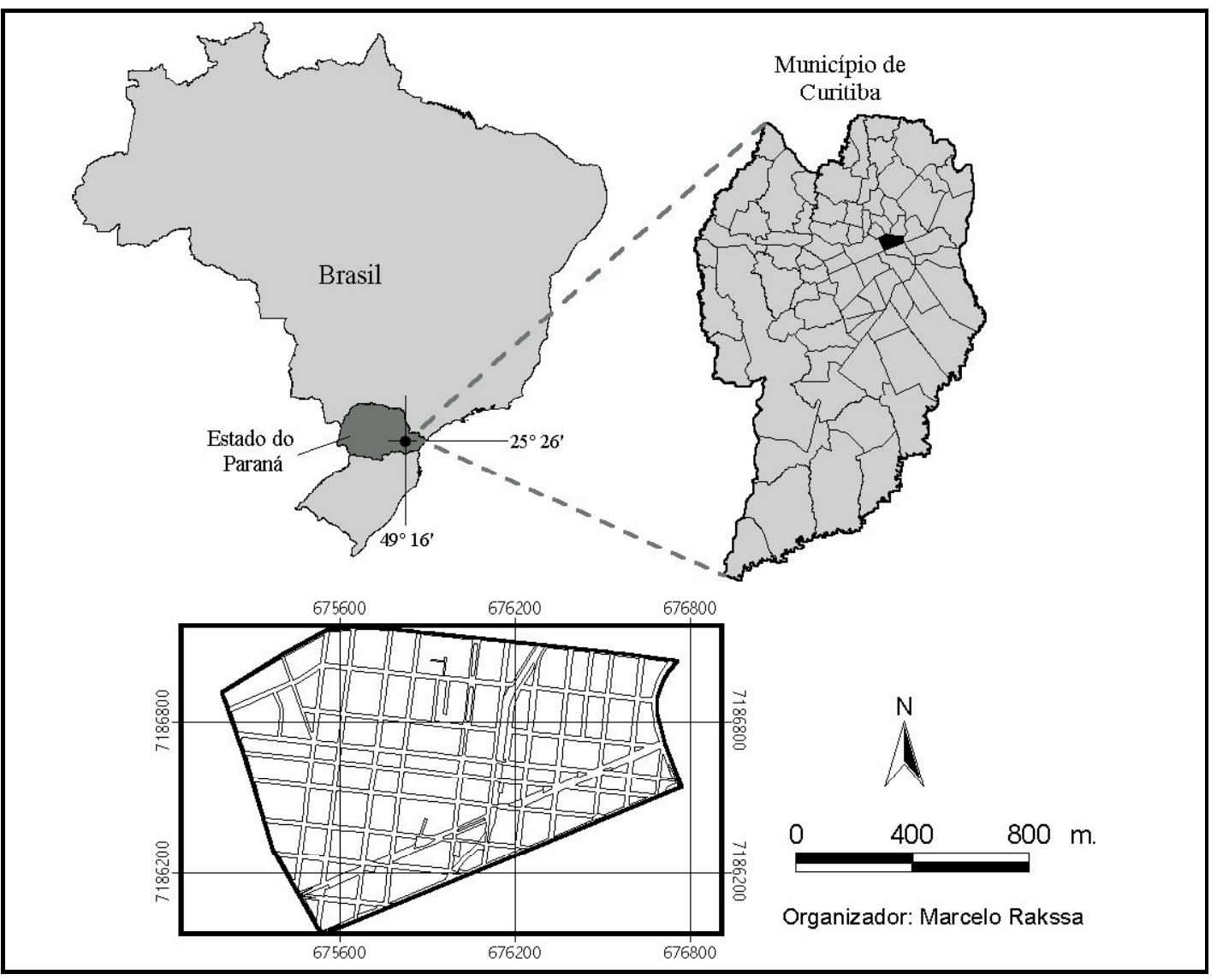

Figura 3 Localização do bairro Alto da XV, Curitiba (PR).

Pesquisa e Planejamento Urbano de Curitiba (IPPUC), foram confeccionas e interpretadas e, com auxilio de trabalho de campo, os espaços livres foram identificados e mapeados na carta base 1:10.000.

3. Com uma folha de acetato sobre as cópias das fotografias aéreas (1:10.000) e uma caneta retroprojetora de ponta fina $(0.5 \mathrm{~mm})$, foram obtidas, as manchas de vegetação visíveis nessa escala, bem como os limites da área de estudo.

4. Com papel vegetal milimetrado foram calculados o tamanho da área de estudo e também a área ocupada pela cobertura vegetal. Todos os cálculos foram feitos com base nas cópias das fotografias aéreas, embora estas apresentem distorções. Para se trabalhar com uma estimativa de área mais próxima da realidade, a área total da cobertura vegetal foi transformada em porcentagem e esse valor foi utilizado para 0 cálculo da área total da cobertura vegetal.
5. As formas e distribuição das manchas de cobertura vegetal foram classificadas de acordo com JIM (1989), Fig. 2.

6. Cada espaço livre identificado e mapeado foi analisado e classificado ou não como área verde, de acordo com os conceitos sugeridos por CAVALHEIRO et al. (1999), Fig. 1.

7. As áreas dos espaços livres foram calculadas na carta base (CURITIBA, 2003), na escala 1:5.455 e fornecida pelo IPPUC.

8. Os espaços livres foram avaliados levando-se em consideração o tamanho, o estado de conservação, a relação entre superfícies permeáveis e impermeáveis, a potencialidade da vegetação em regular o clima local e o balanço hídrico, bem como seu papel protetor contra ruídos; também foi observado 0 potencial para o uso com base nas oportunidades para se obter experiências recreativas e educacionais, principalmente, em contato com a natureza (terra, plantas, animais, ar fresco, água

2 Para facilitar a avaliação da qualidade dos espaços livres em relação às funções ecológicas, estéticas e de lazer, seriam bem oportunas pesquisas que pudessem organizar, de forma clara e de fácil utilização, os necessários critérios de qualidade. Em PRESOTTO (2004), pode-se encontrar uma planilha elaborada por CAVALHEIRO (2002) como ponto de partida para a avaliação de espaços livres. 
limpa, banho de sol, etc.). A avaliação foi realizada por meio de visitas e simples observações dos espaços livres, procurando verificar o cumprimento das funções ecológicas, estéticas e de lazer, como coloca CAVALHEIRO et al. (1999)2.

9. Com base nos dados de população do IBGE (2000) e nas áreas dos espaços livres, áreas verdes e cobertura vegetal, foram calculados os índices em metros quadrados por habitante.

\section{Resultados e Discussão \\ Cobertura Vegetal}

Na Fig. 4 encontram-se o levantamento e a distribuição da cobertura vegetal no bairro Alto da XV.

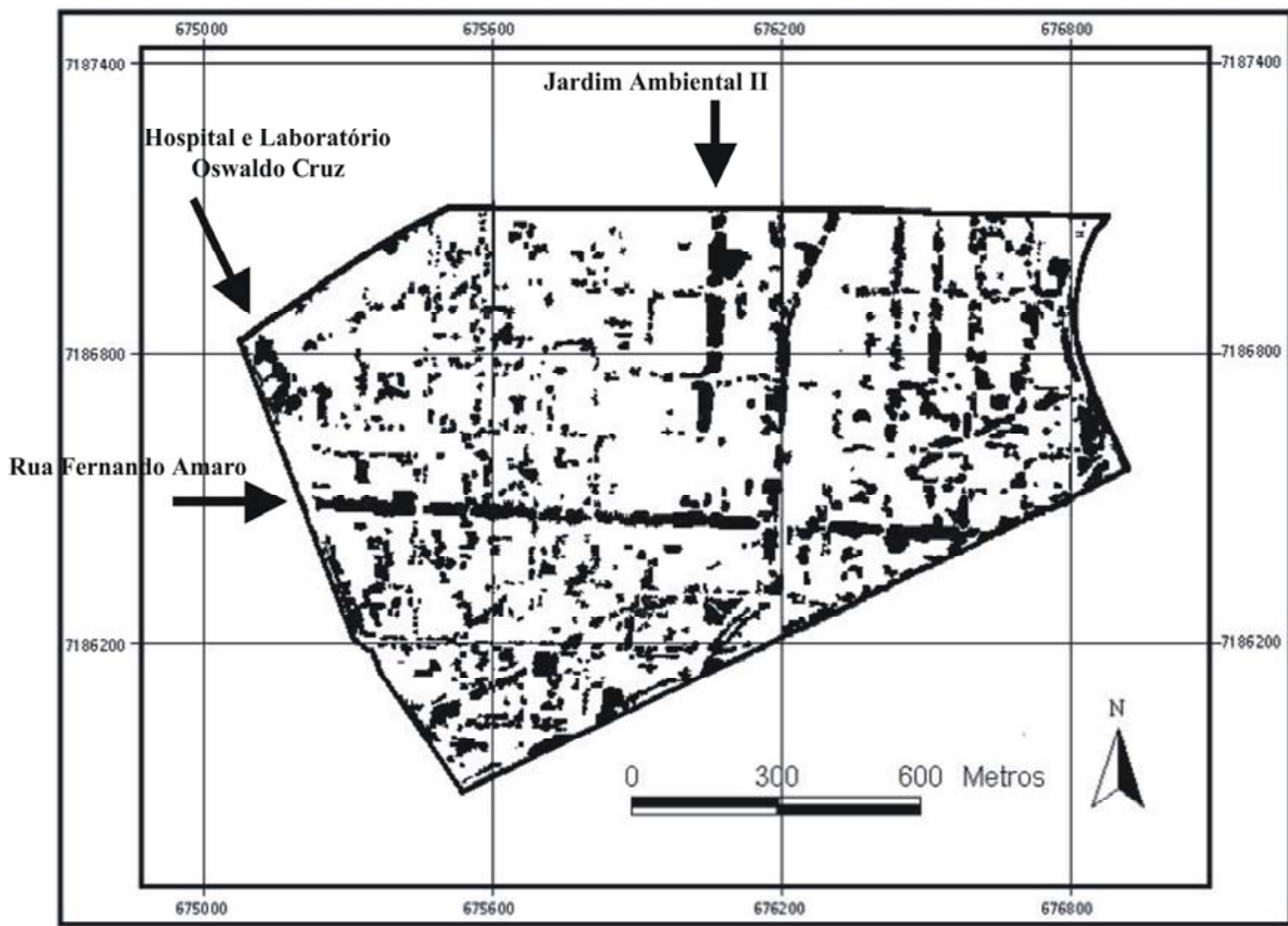

Legenda

Fonte: IPPUC, 2000.

Fotografias Aéreas: Fx 08, Fiducial

Ltda, P.M.C./COHAB, dez/02

Cobertura vegetal

Organização: Rakssa \& Buccheri, 2004.

Figura 4 Distribuição espacial da cobertura vegetal no bairro Alto da XV (Fonte: base cartográfica IPPUC, 2000. Fotografias Aéreas: Fx 08, Fiducial Ltda, P.M.C./COHAB, dez/02. Organização: RAKSSA e BUCCHERI, 2004).

Observando a Fig. 4, percebe-se a existência, na Rua Fernando Amaro e no Jardim Ambiental II situado na Rua Schiller, duas manchas quase contínuas de vegetação formadas pelas copas de grandes árvores localizadas nas calçadas, em sua maioria do gênero Tipuana sp. Outra grande mancha contínua de vegetação está localizada nos jardins do Hospital e Laboratório Oswaldo Cruz, localizado na Rua Ubaldino do Amaral, entre as ruas Amintas de Barros e rua XV de Novembro.
Utilizando a classificação de JIM (1989), baseada nas formas e distribuição espacial de manchas de vegetação (Fig. 2), verificou-se que o bairro Alto da XV não possui conectividade suficiente entre as manchas de cobertura vegetal, sendo predominantemente caracterizado pelo tipo Isolated com a variante Clustered em sua maioria, apresentando apenas duas manchas que merecem destaque: uma caracterizada pelo tipo Isolated com variante Clumped que se estende do norte até 0 
centro do bairro e outra do tipo Linear com a variante Rectilinear encontrada no sentido leste-oeste do bairro.

Sobre a quantificação, constatou-se que o bairro Alto da XV apresenta o valor de $16,85 \%$ de cobertura vegetal, ou seja, $219.158,92 \mathrm{~m}^{2}$. Dividindo-se este valor $\left(219.158,92 \mathrm{~m}^{2}\right)$ pelo número de habitantes do bairro (8.683 habitantes - IBGE, Censo, 2000), chegou-se ao índice de $25,24 \mathrm{~m}^{2}$ de cobertura vegetal/hab. Comparando esses valores com outras localidades (Tab. 1), verifica-se que o bairro Alto da XV possui um índice mais elevado de cobertura vegetal.

Um ponto agravante a ser considerado diz respeito às áreas desprovidas de vegetação. Estas possuem cobertura vegetal abaixo de $5 \%$, principalmente, no interior das quadras que são quase totalmente edificadas, e poderiam ser consideradas como semelhantes a "desertos" (OKE, 1973 apud LOMBARDO, 1985). Talvez o termo mais apropriado para a realidade do bairro seria "desertos florísticos" (DOUGLAS, 1983), já que, mesmo sem vegetação, o clima da região não se assemelha às condições de um deserto.

\section{Espaços Livres e Áreas Verdes}

Foram encontrados sete espaços livres públicos, sendo uma praça (Praça das Nações), quatro jardinetes (Jardinete Cleusa Salomão, Jardinete Des. Zeferino Krukoski, Jardinete Natálio Santos e Jardinete Aline Cordeiro P. de Souza) e duas áreas nomeadas pela Prefeitura de Curitiba como jardim ambiental (Jardim Ambiental I e Jardim Ambiental II) ${ }^{3}$.
A Fig. 5 mostra a localização e a quantificação dos sete espaços livres públicos no bairro Alto da XV. A Tab. 3 aponta a caracterização e classificação dos espaços livres públicos segundo sua área, função e qualidade.

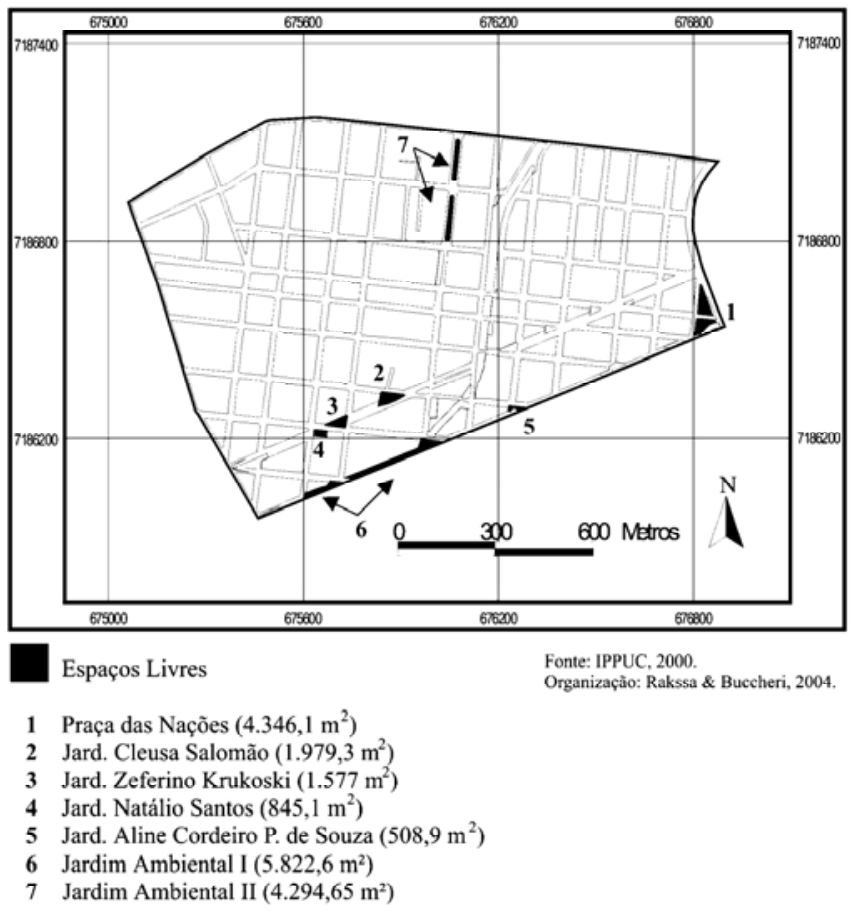

Figura 5 Localização e quantificação dos espaços livres públicos no bairro Alto da XV.

Tabela 3 Caracterização e classificação dos espaços livres do bairro Alto da XV.

\begin{tabular}{l|c|c|c|c}
\hline \multicolumn{1}{c|}{ Nome } & Área $\left(\mathrm{m}^{2}\right)$ & Funções & Classificação & Qualidade \\
\hline 1. Praça das Nações & $4.346,10$ & $\mathrm{Ec}, \mathrm{Es}, \mathrm{L}$ & Área verde & Muito Boa \\
\hline 2. Jard. Cleusa Salomão & $1.979,30$ & $\mathrm{Ec}, \mathrm{Es}, \mathrm{L}$ & Área verde & Boa \\
\hline 3. Jard. Zeferino Krukoski & $1.577,00$ & $\mathrm{Ec}, \mathrm{Es}, \mathrm{L}$ & Área verde & Boa \\
\hline 4. Jard. Natálio Santos & 845,1 & $\mathrm{Es}, \mathrm{L}$ & Espaço livre & Regular \\
\hline 5. Jard. Aline Cordeiro P. de Souza & 508,9 & $\mathrm{~L}$ & Espaço livre & Ruim \\
\hline 6.Jardim Ambiental I & $5.822,60$ & $\mathrm{Ec}, \mathrm{Es}, \mathrm{L}$ & Espaço livre & Boa \\
\hline 7.Jardim Ambiental II & $4.294,65$ & $\mathrm{Ec}, \mathrm{Es}, \mathrm{L}$ & Espaço livre & Boa \\
\hline TOTAL & $19.373,65$ & - & - & Org. Buccheri (2004). \\
"Funções: Ecológica (Ec), Estética (Es), Lazer (L).
\end{tabular}

\footnotetext{
${ }_{3}^{3}$ Praça: espaço para lazer com área superior a $2.500 \mathrm{~m}^{2}$. Jardinete: espaço para lazer com área inferior a $2.500 \mathrm{~m}^{2}$. Jardim Ambiental: ruas fechadas com equipamentos para lazer. Fonte: Sra. Eliane do Departamento de Parques e Praças da Secretaria Municipal do Meio Ambiente de Curitiba (Comunicação pessoal em 15/02/2005).
} 
Dos sete espaços livres encontrados na área de estudo, três podem ser considerados como área verde (espaços livres onde há predominância de vegetação e onde há possibilidades de lazer em contato com a natureza).

Dividindo-se a quantidade de espaços livres públicos $\left(19.373,65 \mathrm{~m}^{2}\right)$ pelo número de habitantes (8.683 habitantes, IBGE, 2000), obteve-se índice de $2,23 \mathrm{~m}^{2}$ de espaço livre público por habitante. Estas áreas de espaços livres públicos representam $1,49 \%$ da área total do bairro.

Verificou-se que dos 19.373,65 $\mathrm{m}^{2}$ de espaços livres públicos, apenas $7.902,4 \mathrm{~m}^{2}$ poderiam ser considerados áreas verdes, o que representa $0,60 \%$ da área total do bairro. Dividindo a quantidade de área verde $\left(7.902,4 \mathrm{~m}^{2}\right)$ pelo número de habitantes do bairro, chegou-se ao índice de $0,90 \mathrm{~m}^{2}$ de área verde por habitante.

$\mathrm{Na}$ Tab. 4 estão organizados os índices obtidos no levantamento dos espaços livres, das áreas verdes e da cobertura vegetal no bairro Alto da XV.

Tabela 4 Índices de espaços livres, áreas verdes e cobertura vegetal no bairro Alto da XV.

\begin{tabular}{c|c|c|c}
\hline $\begin{array}{c}\text { Tipo de Verde } \\
\text { Urbano }\end{array}$ & Área $\left(\mathrm{m}^{2}\right)$ & $\begin{array}{c}\text { Porcentagem do bairro } \\
(\%)\end{array}$ & $\begin{array}{c}\text { Índice } \\
\left(\mathrm{m}^{2} / \mathrm{hab}\right)\end{array}$ \\
\hline Espaços livres & $19.373,65$ & 1,49 & 2,23 \\
\hline Áreas verdes & $7.902,40$ & 0,60 & 0,91 \\
\hline Cob. Vegetal & $219.193,95$ & 16,85 & 25,24 \\
\hline
\end{tabular}

Area total do bairro Alto da XV: 1.300.854,3 m². População total (Censo IBGE, 2000) do bairro Alto da XV: 8.683 habitantes.

Organização: Buccheri (2004).

É importante ressaltar a confusão sobre o índice de áreas verdes, quando estes não estão ligados a um conceito préestabelecido. Em sua página de Internet, o Instituto de Pesquisa e Planejamento Urbano de Curitiba (IPPUC, 2003) apresenta 0 valor de $12.086,47 \mathrm{~m}^{2}$ de área verde para o bairro Alto da XV, sendo que a pesquisa realizada neste trabalho encontrou 7.902,4 $\mathrm{m}^{2}$ de área verde para o bairro. Como 0 índice fornecido pelo IPPUC (2003) não apresenta nenhuma referência sobre qual 0 conceito utilizado para se definir área verde nem como foi realizado o levantamento para se chegar ao número de 12.086,47 $\mathrm{m}^{2}$ de área verde, torna-se impossível qualquer tipo de comparação.

Um outro problema encontrado nos dados sobre áreas verdes, cedidos pelo IPPUC (2003) em sua página na Internet, relaciona-se ao índice em $\mathrm{m}^{2}$ em área verde por habitante. Segundo o Censo do IBGE (2000), cedido pelo próprio IPPUC (2003) para consulta em sua página na Internet, existem 8.683 habitantes no bairro Alto da XV. Se, segundo o IPPUC, existem $12.086,47 \mathrm{~m}^{2}$ de área verde e 8.683 pessoas no bairro Alto da XV, deveriam existir $1,39 \mathrm{~m}^{2}$ de área verde/habitante, e não $0,19 \mathrm{~m}^{2}$ de área verde/habitante como informado pelo IPPUC (2003).

Este fato, mais uma vez comprova, como afirma NUCCl (2001), que um índice desacompanhado da definição dos termos, da escala espacial e do método de coleta dos dados não estabelece parâmetros de comparação.

\section{Considerações Finais}

De modo geral, pode-se considerar que o índice de 16,85\% de cobertura vegetal para o bairro Alto da XV foi o maior até agora encontrado nos estudos realizados com técnicas semelhantes, mas que ainda não atinge os valores de $30 \%$ propostos na literatura para as regiões centrais das cidades.

Apesar de um índice de cobertura vegetal mais elevado, os índices de espaços livres $(1,49 \%)$ e de áreas verdes $(0,60 \%)$ para o Alto da XV, são inferiores aos encontrados no levantamento realizado no distrito de Santa Cecília em São Paulo (NUCCl, 2001). Porém, devido à baixa densidade demográfica, os valores em $\mathrm{m}^{2} / \mathrm{hab}$. são mais elevados. Essa constatação mostra que 0 bairro Alto da XV é bem arborizado, mas não garante as oportunidades de lazer necessárias, pois a concentração dos espaços livres e das áreas verdes em algumas partes específicas torna-se um fator que dificulta 0 acesso pela população.

Os espaços livres, as áreas verdes e a cobertura vegetal são elementos fundamentais para um planejamento urbano que se preocupa com a qualidade ambiental, sendo o poder público quem deve planejar, criar e ajudar a manter ambientes agradáveis e estéticos, dentro dos padrões aceitáveis para uma vida saudável dos moradores, deixando aos cidadãos a escolha de onde querem passar suas horas de lazer.

É importante ressaltar a necessidade das pessoas estarem em contato com a natureza, mesmo nas áreas urbanizadas e que este contato não demande a locomoção por longas distâncias.

A comunidade e o poder público poderiam discutir sobre a quantidade, qualidade e distribuição dos espaços livres, das áreas verdes e da cobertura vegetal do bairro, com o intuito de se alcançar os índices considerados ideais. 
BUCCHERI FILHO, A.T.; NUCCI, J.C. (2006). Open spaces, green areas and tree canopy coverage in the Alto da XV district, Curitiba/PR. Revista do Departamento de Geografia, n. 18, p. 48-59

Abstract: Among corporations of research, education, planning and scientific societies we find different versions of terms for green area, open space, vegetative cover, areas destined to nature conservation, urban forest, etc. This paper shows and uses, for a district of Curitiba City (PR), a classification proposition to open spaces and urban green areas, as a suggestion to concepts, methods and techniques to the urban landscape planning.

Keywords: Open space; Green area; Vegetative cover; Curitiba.

Recebido em 16 de agosto de 2004, aceito em 25 de junho de 2005.

\section{Referências}

ANDREWS, W.A. (1976) A Guide to Urban Studies. Ontário: Prentice-Hall, 293p.

BRASIL. Lei Federal n. 10.257, de 10 de Julho de 2001. Estatuto da cidade. Disponível em: <http://www.estatutodacidade. org.br/>. Acesso em: 14 de março de 2003.

CAVALHEIRO, F.; DEL PICCHIA, P.C.D. (1992) Áreas verdes: conceitos, objetivos e diretrizes para o planejamento. In: Encontro Nacional Sobre Arborização Urbana, 4 Vitória (ES), de 13 a 18 de setembro de 1992, Anais I ell, p.29-38.

CAVALHEIRO, F.; NUCCI, J.C; GUZZO, P.; ROCHA, Y.T. (1999) Proposição de terminologia para o verde urbano. Boletim Informativo da SBAU (Sociedade Brasileira de Arborização Urbana), ano VII, n. 3 - jul/ago/set de 1999, Rio de Janeiro, p. 7.

CAVALHEIRO, F.; PRESOTTO, A.; ROCHA, Y.T. (2003) Planejamento e projeto paisagístico e a identificação de unidades de paisagem: o caso da Lagoa Seca do bairro Jardim América, Rio Claro (SP). GEOUSP - Espaço e Tempo, no 13, p. 161-167, 2003.

CURITIBA. Decreto Municipal $n^{0}$ 774/75. Instituto de Planejamento e Pesquisa de Curitiba (IPPUC), elaboração: jan/2003 - escala 1:10.000.

DIAS, G.F. (2002) Pegada Ecológica e sustentabilidade humana. São Paulo: Gaia, 257p.

DOUGLAS, I. (1983) The urban environment. London: Edward Arnold, 229p.

HARDT, L.P.A. (1994) Subsídios ao planejamento de sistemas de áreas verdes baseado em princípios de ecologia urbana: aplicação à Curitiba - PR. Dissertação de mestrado em Eng. Florestal - UFPR, Curitiba.
HENKE-OLIVEIRA, C.; CAVALHEIRO, F.; SANTOS, J.E.; ALBRECHT, J.M.F., CASTILHO, H.J.; FOSCHINI, M.T.C.; SÁ, O.R.; SILVA, R.T.; LIMA, R.N.; SILVA, R.L.; SANTOS, S.M.; BARBOSA, R.M. (1994) Caracterização preliminar das áreas verdes públicas em São Carlos - SP. In: II CONGRESSO NACIONAL SOBRE ARBORIZAÇÃO URBANA, São Luís, de 18 a 24 de setembro de 1994.

IPPUC. Disponível em: <http:// www.ippuc.org.br> Acesso em: 14 de março de 2003.

JIM, C.Y. (1989) Tree-canopy characteristics and urban development in Hong Kong. The Geographical Review, v.79, n.2. Lawrence: American Geographical Society, pp. 210-255.

LEFEBVRE, H. (1969) O direito à cidade. São Paulo: Nacional.

LIMA, A.M.L.P.; CAVALHEIRO, F.; NUCCI, J.C.; SOUZA, M.A. del B.; FIALHO, N. de O.; DEL PICCHIA, P.C.D. (1994) Problemas de utilização na conceituação de termos como espaços livres, áreas verdes e correlatos. In: II CONGRESSO BRASILEIRO DE ARBORIZAÇÃO URBANA, São Luís, de 18 a 24 de setembro de 1994, p. 539-549.

LOMBARDO, M.A. (1985) Ilha de calor nas metrópoles. O exemplo de São Paulo. São Paulo: Hucitec, 244p.

LOMBARDO, M.A. (1990) Vegetação e clima. In: III ENCONTRO NACIONAL SOBRE ARBORIZAÇÃO URBANA, Curitiba-PR, FUPEF/PR, p. 1-13.

MARCUS, M.G., DETWYLER, T.R. (1972) Urbanization and environment. Bermont/Cal., Duxburg Press, 286p.

MONTEIRO, C.A. de F. (1976) Teoria e clima urbano. São Paulo: IGEOG/USP, 1976, 181p.

NUCCI, J.C. (2001) Qualidade ambiental e adensamento urbano. São Paulo: Humanitas/FAPESP, 236p.

NUCCI, J.C.; CAVALHEIRO, F. (1999) Cobertura vegetal em áreas urbanas - conceito e método. GEOUSP 6, São Paulo: Depto. de Geografia/USP, pp. 29-36. 
NUCCI, J.C.; LOPES, M.P.; CAMPOS, F.P. de; ALVES, U.M.; MANTOVANI, M. (2000) Áreas verdes de Guarulhos/SP classificação e quantificação. GEOUSP 8, São Paulo: Depto. de Geografia/USP, pp. 9-15.

NUCCI, J.C.; ITO, K.M. (2002) Cobertura vegetal do bairro Jardim Tranqülidade (Guarulhos/SP). $13^{\circ}$ ENCONTRO DE BIÓLOGOS DO CONSELHO REGIONAL DE BIOLOGIA (CRBio-1/SP, MT, MS). Resumos..., São Pedro/SP, de 25 a 28 e março de 2002.

NUCCI, J.C; WESTPHALEN, L.A.; BUCCHERI FILHO, A.T.; NEVES, D.L.; OLIVEIRA, F.A.H.D.; KRÖKER, R. (2003) Cobertura vegetal no bairro Centro de Curitiba/PR. GEOUERJ, número especial, Rio de Janeiro, 2003 (CDROM).
PRESOTTO, A. (2004) Espaços livres públicos: um estudo no município de llhabela (SP). Dissertação de mestrado em Geografia Física - DG-FFLCH-USP, São Paulo, 2004.

ROCHA, A.A. (1991) Do lendário Anhembi ao poluído Tietê. São Paulo: EDUSP, 75p.

RUSZCZYK, A. (1986) Análise da cobertura vegetal da cidade de Porto Alegre, RS. Revista Brasileira de Botânica 9:225-229.

SUKOPP, H; BLUME, H.P.; KUNICK, W. (1979) The soil, flora and vegetation of Berlin's waste lands. In: Laurie, I.C. (Ed.): Nature in cities_Wiley, Chichester, 1979.

SUKOPP, H.; WERNER, P.(1991) Naturaleza en las ciudades. Madrid, 1991. 